University of Nebraska - Lincoln

DigitalCommons@University of Nebraska - Lincoln

Relationship Between Soil Moisture of Near Surface and Multiple Depths of the Root Zone Under Heterogeneous Land Uses and Varying Hydroclimatic Conditions

\author{
Rezaul Mahmood \\ University of Nebraska - Lincoln
}

Follow this and additional works at: https://digitalcommons.unl.edu/natrespapers

Part of the Natural Resources and Conservation Commons, Natural Resources Management and Policy Commons, and the Other Environmental Sciences Commons

Mahmood, Rezaul, "Relationship Between Soil Moisture of Near Surface and Multiple Depths of the Root Zone Under Heterogeneous Land Uses and Varying Hydroclimatic Conditions" (2007). Papers in Natural Resources. 1270.

https://digitalcommons.unl.edu/natrespapers/1270

This Article is brought to you for free and open access by the Natural Resources, School of at DigitalCommons@University of Nebraska - Lincoln. It has been accepted for inclusion in Papers in Natural Resources by an authorized administrator of DigitalCommons@University of Nebraska - Lincoln. 


\title{
Relationship between soil moisture of near surface and multiple depths of the root zone under heterogeneous land uses and varying hydroclimatic conditions
}

\author{
Rezaul Mahmood ${ }^{1 *}$ and Kenneth G. Hubbard ${ }^{2}$ \\ ${ }^{1}$ Department of Geography and Geology and Kentucky Climate Center, Western Kentucky University, Bowling Green, KY 42101, USA \\ ${ }^{2}$ High Plains Regional Climate Center, School of Natural Resource Sciences, University of Nebraska-Lincoln
}

\begin{abstract}
:
This paper presents an assessment of the relationship between near-surface soil moisture (SM) and SM at other depths in the root zone under three different land uses: irrigated corn, rainfed corn and grass. This research addresses the question whether or not near-surface SM can be used reliably to predict plant available root zone SM and SM at other depths. For this study, a realistic soil-water energy balance process model is applied to three locations in Nebraska representing an east-to-west hydroclimatic gradient in the Great Plains. The applications were completed from 1982 through to 1999 at a daily time scale. The simulated SM climatologies are developed for the root zone as a whole and for the five layers of the soil profile to a depth of $1.2 \mathrm{~m}$.

Over all, the relationship between near-surface SM $(0-2.5 \mathrm{~cm})$ and plant available root zone SM is not strong. This applies to all land uses and for all locations. For example, $r$ estimates range from 0.02 to 0.33 for this relationship. Results for nearsurface SM and SM of several depths suggest improvement in $r$ estimates. For example, these estimates range from $-0 \cdot 19$ to 0.69 for all land uses and locations. It was clear that $r$ estimates are the highest $(0.49-0.69)$ between near-surface and the second layer $(2.5-30.5 \mathrm{~cm})$ of the root zone. The strength of this type of relationship rapidly declines for deeper depths. Cross-correlation estimates also suggest that at various time-lags the strength of the relationship between near-surface SM and plant available SM is not strong. The strength of the relationship between SM modulation of the near surface and second layer over various time-lags slightly improves over no lags. The results suggest that use of near-surface SM for estimating SM at $2 \cdot 5-30 \mathrm{~cm}$ is most promising. Copyright $\left(C^{\circ} 2007\right.$ John Wiley \& Sons, Ltd.
\end{abstract}

KEY WORDS soil moisture; modelling; land use

Received 2 April 2006; Accepted 5 September 2006

\section{INTRODUCTION}

Soil moisture (SM) is an important component of the hydrological cycle and a key mediator between land surface and atmospheric interactions. Near absence of a high density SM observing network is an obstacle for weather and climate prediction (cf. Koster and Suarez, 2003). Unavailability of long-term homogeneous SM data for various depths of the root zone also prevents the atmospheric science community from better understanding how this quantity varies over different time-scales under different land uses within heterogeneous hydroclimatic domains. Subsequently, we encounter the question regarding the impacts of these variabilities on atmospheric modulation and its prediction. Modelling of SM and creating a long-term data set can be used to answer some of these questions. In the past, the authors of this paper have addressed issues related to SM variability at different time-scales under different hydroclimatic regimes, land uses and through the various depths of the

\footnotetext{
* Correspondence to: Rezaul Mahmood, Department of Geography and Geology and Kentucky Climate Center, Western Kentucky University, Bowling Green, KY 42101, USA. E-mail: rezaul.mahmood@wku.edu
}

root zone (e.g. Mahmood and Hubbard, 2004) using longterm modelled data. These activities are in line with other SM modelling efforts (e.g, Global Soil Wetness Project (GSWP)).

This paper addresses issues that are related to the above research themes. In particular, it is concerned with the following questions. Can we correlate near-surface SM to $\mathrm{SM}$ at deeper layers of the root zone or to plant available root zone SM? What is the strength of these correlations? How do these 'correlations' vary under different land uses and soils and during different years? These issues are particularly critical during any attempt to characterize and quantify root zone SM based upon near-surface soil water content. This study uses a soil moisture process model to reconstruct past SM at different depths up to $1.2 \mathrm{~m}$ and investigates the questions presented above under three different land uses (grass, rainfed corn and irrigated corn) and varying hydroclimatic conditions of the Northern Great Plains (NGP) (Figure 1).

Plant-water use varies between phenological stages and with stage duration. This leads to variations in water use from one growing season to the next. Hence, water consumption (thus root zone SM distribution) under various land uses is different under the same climatic conditions (cf. Mahmood and Hubbard, 2002). Note, the 


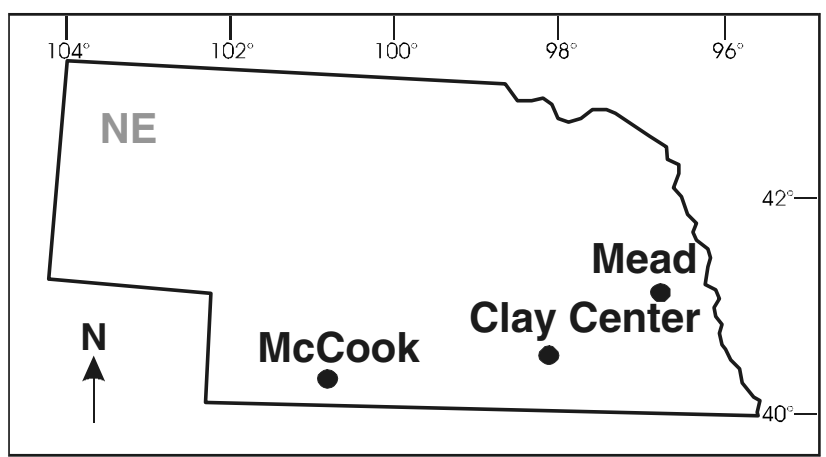

Figure 1. Location of the model applications. (Modified from Mahmood and Hubbard, 2002)

growing season for irrigated corn is longer by 4-6 weeks (than rainfed corn and grass) owing to the availability of moisture to sustain growth later in the season. Thus, for a given growing season, water consumption and root zone SM distribution are different for these land uses. The Robinson and Hubbard (1990) model applications were repeated for three sites in Nebraska for these land uses (Figure 1). The model estimates of SM are for the top five layers to a depth of $122 \mathrm{~cm}$ and for a period from 1982 through 1999. The five layer depths are $0-2 \cdot 5,2 \cdot 5-30 \cdot 5$, $30 \cdot 5-61,61-91.5$ and $91 \cdot 5-122 \mathrm{~cm}$, respectively.

The SM model was successfully validated by Robinson and Hubbard (1990), Camargo (1993), and Camargo et al. (1994). The Robinson-Hubbard model validation was completed for five predominant land uses in the Great Plains including grass, corn, wheat, sorghum and soybean. Nine locations extending from eastern to western Nebraska, South Dakota and Wyoming were used for this purpose. In addition, successful model evaluation for six soil layers up to the depth of $1.8 \mathrm{~m}$ was also conducted. The data collection campaigns consisted of four growing seasons (April through to September/October) in 1986, 1987, 1990 and 1991. The validation efforts were more extensive than those presented in several other modelling efforts. For example, the Variable Infiltration Capacity (VIC) (Cherkauer and Lettenmair, 1999) and the Crawford model (Crawford et al, 2000) were validated by using 1 month of data and only for grass. On the other hand, validation of the Robinson-Hubbard model was completed over a larger geographical area with a wellknown east to west hydroclimatic gradient, over a variety of land uses, and for several growing-seasons. A detailed discussion on the Robinson-Hubbard model performance is presented later.

The Robinson-Hubbard SM model is currently operational and used for SM assessment and irrigation scheduling in the NGP. These authors and others have successfully used the Robinson-Hubbard model for a number of studies focusing on impacts of land use on energy balance, SM and ET (e.g. Meyer et al., 1993a,b; Mahmood et al., 2001, 2002, 2004; Mahmood and Hubbard 2002, 2003, 2004). The present research builds upon the data set developed and used by Mahmood and Hubbard (2004).

\section{CLIMATE AND SM MODELLING}

Over the past decade and a half a number of modelling activities were undertaken to explore the relationship between SM and climate. Dirmeyer et al. (2000) assessed impacts of SM on surface fluxes in three land surface schemes (LSSs) by using the evaporative fraction (EF), which is the ratio between latent heat flux and the sum of latent heat flux and sensible heat flux. They found that the EF is sensitive to SM and land use. They indicate that over forested land the EF is sensitive to SM when the soil is drying. Sensitivity is low under moderately moist to wet soil. Dirmeyer et al. (2000) suggested that the accuracy of measurement and modelling of SM is more important for drying soil and for sparsely vegetated land surface. These results are similar to Mahmood and Hubbard's (2003) findings that the forcing of soil heterogeneity on evapotranspiration (ET) decreases and increases under wet and dry conditions, respectively. In another study, Ronda et al. (2002) found that a bulk approach resulted in higher latent energy flux compared with a quasi-distributed approach under wet conditions and this reverses under dry conditions. The results, again, demonstrate the importance of SM in the accurate calculation of boundary layer characteristics. During a modelling study Findell and Eltahir (2003a) found that wet soil provides a more conducive environment for deep convection compared with dry soils. They also noted positive feedback between SM and moist convection during summer months over the eastern USA (Findell and Eltahir, 2003b).

Wu et al. (2002) used an Illinois SM data set to illustrate that its amplitude decreases with depth. Analyses of composites show seasonal variations of SM are amplified during drought years and SM profile variability is a function of depth. Mahmood and Hubbard (2004) successfully simulated this observation for heterogeneous land uses under varying hydroclimatic conditions over the Great Plains. Li and Islam (2002) also noted that the accuracy of the SM profile retrieval depends on the initial SM condition. For wetter soil conditions the model initialization, based on remotely sensed surface SM, is adequate. For drier soil conditions such an initialization produces larger error, due to the decoupling of near-surface and deeper layer SM. A qualitative visual assessment of Nebraska, USA, SM also provides supporting evidence of these conclusions (High Plains Regional Climate Center (HPRCC), 2005, www.hprcc.unl.edu). In short, these studies demonstrate heterogeneity in SM variations through the various depths of the root zone.

Adegoke and Carleton (2002) established a relationship between measured SM and satellite vegetation indices for the Midwestern region of the USA. They found the association between SM and vegetation indices to be scale dependent with an 8-week lag relationship. These indices are also indicative of vegetation health and this may have an impact on energy partitioning. Implicitly, the results suggest the potential influence of SM on the boundary layer atmospheric energy partitioning. Koster and Suarez 
(2003) investigated the impacts of SM on seasonal temperature and precipitation prediction. Their study finds that land initialization with SM increased forecast skill in certain seasons and geographical regions. In a previous study Koster et al. (2000) found that during summertime SM plays a dominant role in controlling continental precipitation. A modelling study by Schlosser and Milly (2002) suggests that high 30-day-mean temperature predictability was associated with strong variability of SM stress on ET and with abundant continental SM. They also show that skill in predicting monthly near-surface temperature and SM is affected by initial SM.

Hong and Pan (2000) reported a strong positive feedback between initial SM and simulated seasonal precipitation. The simulations were conducted by using the National Centers for Environmental Prediction Regional Spectral Model (NCEP RSM). Model simulations show that soil water storage eventually effects moisture distribution within the boundary layer atmosphere and its structure (Hong and Pan, 2000). Wang and Kumar (1998) suggest that interannual variations of SM may play a role in seasonal predictability of surface climate anomalies. They found a strong correlation between SM and surface temperature anomalies. Dirmeyer $(1999,2000)$ also noted that accuracy of simulated precipitation anomaly was lowered due to incorrect SM inputs. Huang et al. (1996) found that SM provides improved prediction, compared with precipitation, of temperature over large areas during the summer season. A number of other studies have also demonstrated that correct SM specification in the models has a direct impact on the forecasting skill (cf. Schar et al., 1999; Hong and Kalnay, 2000; Douville et al., 2001).

A number of sensitivity studies for several Land Surface Schemes (LSS) were conducted under the Global Soil Wetness Project (GSWP) and the Project for Intercomparison of Land-Surface Parameterization Schemes (PILPS) (e. g. Qu et al. 1998; Dirmeyer, 1999; Morrill et al. 1999; Pitman et al., 1999). Lohmann et al. (1998) noted that simulated changes in mean seasonal cycles of soil moisture storage agreed qualitatively with observations. In other words, it will be difficult for researchers and forecasters to confidently quantify soil moisture using these models. To overcome some of the uncertainties in the design of LSSs and to increase the accuracy of the estimated flux and storage of energy and water and to produce global SM data, a new project, Land Data Assimilation System (LDAS) was undertaken (Mitchell et al., 2000). The Atmospheric Model Intercomparison Project (AMIP) reported that none of the AMIP models capture interannual variations in SM (Robock et al., 1998). Estimates of SM provided by the revised AMIP models also show no improvement in reflected actual seasonal variations in SM (Srinivasan et al., 2000). The GSWP used 10 LSSs to produce global SM data. It is noted that none of the models produced realistic estimates of SM for any regions (Entin et al., 1999). They observed that model biases vary from region to region and a simple approach would not be sufficient.
In summary, earlier studies did not explicitly assess the relationship between near-surface and root zone SM at various depths. This type of assessment is essential in estimating root zone SM. In addition, the absence of data has been a barrier to obtaining a better grasp of $\mathrm{SM}$ dynamics at different depths within the top $1 \mathrm{~m}$ of the soil profile. Also, SM variations under a number of widespread land use/land cover types and the absence of a concurrent evaluation has been a barrier to better understanding of SM and its relationship to climate.

The present study quantifies the relationship between near-surface and SM at various depths. This objective is fulfilled by using long-term modelled data from three hydroclimatically different locations where three different land uses are assumed at each location. This study is particularly critical for a number of reasons. First, it allows us to understand the SM relationships between near-surface and various depths of root zone. Second, we explore these relationships under varying land uses, soils and hydroclimatic conditions. Third, these assessments were conducted over various time-scales. Fourth, this study presents the opportunity to visit the issues related to reliable estimation of root zone SM based on nearsurface SM.

Due to the extensive conversion of natural grasslands to agricultural land use in the Great Plains, it is essential that we investigate the SM of crop lands along with grasslands. Applications of the Robinson-Hubbard model are advantageous because it is well-adapted to local (the NGP) land use and hydroclimatic conditions. It is noted that the relationship between land use and soil moisture must be assessed under a variety of conditions (Qiu et al., 2001) and this study addresses this concern. In addition, the United States Global Change Research Program (USGCRP) notes that improved understanding of water cycle variations at the climatological time-scale is a critical research issue (USGCRP, 2001). As a result, the long-term goal of the authors of this paper is to address this objective as identified by the USGCRP. In addition, this study has been carried out within the Mississippi watershed which is the focus of GEWEX Americas Prediction Project (GAPP) area.

\section{ROBINSON-HUBBARD SM MODEL AND EVALUATION OF ITS PERFORMANCE}

The Robinson-Hubbard SM model can be presented as follows:

$$
\partial S / \partial t=P+I-E T-R_{0}-D_{\mathrm{r}}
$$

where $S$ is soil water in the root zone $(\mathrm{mm}), t$ is time (day), $P$ is precipitation, $I$ is irrigation, $E T$ is actual evapotranspiration, $R_{0}$ is runoff and $D_{\mathrm{r}}$ is drainage below the root zone, all in daily time frame $\left(\mathrm{mm} \mathrm{day}^{-1}\right)$. Total precipitation, relative fraction of soil water present, and a soil water retention factor are used to estimate runoff (McCuen, 1982). The model uses Campbell's 
equation to calculate drainage (Campbell, 1985; p. 92, equation 8.37).

Evaporation and transpiration are first estimated and then ET is taken as the sum of these two. A modified Penman (Penman, 1948) combination method of potential $E T$ estimation is used to derive $E$ and $T$. In this modification, a wind function developed by Kincaid and Heerman (1974) is used. In this model, evaporation is also a function of number of days $(N D)$, where $N D$ is set to 1 on the day of precipitation (or irrigation) and increases by one for each consecutive day. The relationships among evaporation, potential $E T$ and $N D$ can be presented as follows:

$$
E=E T_{\mathrm{p}}(1 / N D)^{1 / 2}
$$

where $E T_{\mathrm{p}}$ is potential evapotranspiration based on the modified Penman method.

Transpiration is a function of a crop and phenologically dependent crop-coefficient $\left(K_{\mathrm{c}}\right), E T_{\mathrm{p}}$, and a soilwater reduction factor $(f)$. The soil-water reduction factor restricts crop-water use when soil moisture content approaches wilting point and is a function of available soil water and water holding capacity of the soil (Robinson and Hubbard, 1990). Hence, transpiration in the model is:

$$
T=(f)\left(K_{\mathrm{c}}\right)\left(E T_{\mathrm{p}}-E\right)
$$

The root depth increases linearly with accumulated growing degree-days (GDD). The model divides the plant root zone in four equal layers and assumes $40 \%, 30 \%$, $20 \%$ and $10 \%$ water extraction from each layer, respectively. The soil moisture model simulates water in each layer, current water stress, runoff, drainage, phenology, actual and potential evapotranspiration, sensible heat flux and net radiation.

Here we present a summary of the Robinson-Hubbard model validation activities. The model performance was evaluated during the four growing seasons of 1986, 1987, 1990 and 1991 (Table I). It included observed data from five land uses, nine sites (representing varied soil conditions), and six soil layers up to $1.8 \mathrm{~m}$ depth (cf. Robinson and Hubbard, 1990; Camargo, 1993; Camargo et al., 1994). Tables I-III (and see Figure 3) present details of the model validation from Robinson and Hubbard (1990). The sites are located in Nebraska (five), South Dakota (two), and Wyoming (two) (Table I). Soil water was measured at six depths including 15, 45, $75,105,135$ and $165 \mathrm{~cm}$ using neutron probes and the assumption that the data from each depth represent a soil layer of $30 \mathrm{~cm}$. Each of the nine locations represents different root zone soil characteristics and thus, if we combine location and land use, SM data was collected from 20 different land surface conditions (Table I).

A number of model performance evaluation methods, including the $d$ index (index of agreement), are used (Table II). The $d$ index (Willmott, 1981; Legates and McCabe, 1999), can be expressed as follows:

$$
d=1 \cdot 0-\left(\frac{\sum_{i=1}^{N}\left(O_{i}-P_{i}\right)^{2}}{\sum_{i=1}^{N}\left(\left|P_{i}-\bar{O}\right|+\left|O_{i}-\bar{O}\right|\right)^{2}}\right)
$$

where $O$ and $P$ are observed and predicted values, respectively. The $d$ index penalizes the model for consistently over- or underestimating even though the correlations may be high (Legates and McCabe, 1999). This index ranges from 0.0 to $1 \cdot 0$. Higher values indicate better agreement between modelled and measured values. It is found that for most of the land uses the $d$ index is greater than 0.90 and ranged between 0.7 and 1.0 (Table II).

\begin{tabular}{|c|c|c|c|c|}
\hline Site & Year & $\begin{array}{l}\text { Land } \\
\text { use }\end{array}$ & $\begin{array}{l}\text { Number of days } \\
\text { with measured water }\end{array}$ & Dates of measurement \\
\hline \multirow[t]{2}{*}{ North Platte, NE } & \multirow[t]{2}{*}{1986} & Corn & 13 & June: 4, 11, 18, 25; July: 2, 9, 16, 23, 30; August: 13, 20, 27; Sept: 3 \\
\hline & & Wheat & 12 & April: 23,30 ; May: 7, 14, 21, 28; June $4,11,18,25 ;$ July: 2,9 \\
\hline \multirow[t]{4}{*}{ North Platte, NE } & \multirow[t]{4}{*}{1987} & Corn & 12 & June: $2,11,17$; July: $7,14,21,27$; August: $4,11,18$; Sept: 1,8 \\
\hline & & Wheat & 4 & May: 26, June: 2, 11, 17 \\
\hline & & Sorghum & 12 & June: $2,10,17$; July: $7,14,21,27$; August: $4,11,18 ;$ Sept: 1,8 \\
\hline & & Soybean & 12 & June: $2,10,17$; July: $7,14,21,28$; August: $4,11,18 ;$ Sept: 1,8 \\
\hline \multirow[t]{4}{*}{ Clay Center, NE } & \multirow[t]{4}{*}{1987} & Corn & 8 & June: 30; July: 7, 21, 30; August: 6, 21, 27; Sept.: 30 \\
\hline & & Wheat & 9 & April: 23, 29; May; 7, 15, 29; June: 9, 18, 30; July: 7 \\
\hline & & Sorghum & 8 & June: 30; July: 7, 21, 30; August: 6, 21, 27; Sept.: 30 \\
\hline & & Soybean & 8 & June: 30; July: 7, 22, 30; August: 6, 21, 27; Sept.: 30 \\
\hline \multirow[t]{3}{*}{ Concord, NE } & \multirow[t]{3}{*}{1987} & Corn & 11 & June: 11,25 ; July: 1, 9, 16, 23, 30; August: 5, 14; Sept.: 11, 28 \\
\hline & & Sorghum & 9 & July: 1, 8, 16, 23, 30; August: 5, 14; Sept.: 11, 28 . \\
\hline & & Soybean & 11 & June: 11, 25; July: 1, 9, 16, 23, 30; August: 5, 14; Sept.: 11, 28 . \\
\hline \multirow[t]{2}{*}{ Mead, NE } & \multirow[t]{2}{*}{1986} & Wheat & 5 & May 14, 30; June: 13; July: 2, 16 \\
\hline & & Soybean & 5 & June: 6,$13 ;$ July: 2, 17, 29 \\
\hline Brookings, SD & 1987 & Corn & 4 & June: 29; July: 13; August: 6, 26 \\
\hline Chamberlin, SD & 1987 & Corn & 5 & July: 1, 14, 30; August: 20; Sept.: 14 \\
\hline Wheatland, WY & 1986 & Wheat & 8 & May: 30; June: 15, 30; July: 14, 28; August: 11, 26; Sept.: 8 \\
\hline Sidney, NE & 1987 & Wheat & 8 & May: 27; June: 3, 11, 18, 26; July: 2, 9, 16 \\
\hline Chugwater, WY & 1987 & Grass & 10 & May: 19; June: 2, 10, 16, 23, 30; July: 7, 14, 21, 28 \\
\hline
\end{tabular}
The $r^{2}$ estimates are greater than 0.90 values for 13 out

Table I. Field soil water measurements by location and land use. (Source: Robinson and Hubbard,1990) 
Table II. Performance evaluation of the soil water balance model (Source: Robinson and Hubbard, 1990)

\begin{tabular}{|c|c|c|c|c|c|c|c|c|c|c|c|c|}
\hline Site & Year & Land use & $d$ index & $r^{2}$ & $\begin{array}{l}\text { MAE } \\
(\mathrm{cm})\end{array}$ & $\begin{array}{c}P \\
(\mathrm{~cm})\end{array}$ & $\begin{array}{c}\sigma_{\mathrm{p}} \\
\left(\mathrm{cm}^{2}\right)\end{array}$ & $\begin{array}{c}O \\
(\mathrm{~cm})\end{array}$ & $\begin{array}{c}\sigma_{\mathrm{o}} \\
\left(\mathrm{cm}^{2}\right)\end{array}$ & $\begin{array}{c}E_{\mathrm{s}} \\
(\mathrm{cm})\end{array}$ & $\begin{array}{c}E_{\mathrm{u}} \\
(\mathrm{cm})\end{array}$ & $\begin{array}{c}\text { RMSE } \\
(\mathrm{cm})\end{array}$ \\
\hline \multirow[t]{2}{*}{ North Platte, NE } & \multirow[t]{2}{*}{1986} & Corn & 0.99 & 0.98 & $1 \cdot 2$ & $35 \cdot 4$ & $10 \cdot 2$ & $34 \cdot 6$ & $10 \cdot 3$ & $0 \cdot 8$ & $1 \cdot 3$ & $1 \cdot 5$ \\
\hline & & Wheat & 0.78 & 0.94 & 4.4 & $32 \cdot 1$ & $3 \cdot 8$ & 27.7 & 5.9 & $4 \cdot 8$ & 0.9 & 4.9 \\
\hline \multirow[t]{4}{*}{ North Platte, NE } & \multirow[t]{4}{*}{1987} & Corn & 0.98 & 0.98 & 1.7 & $31 \cdot 0$ & $8 \cdot 8$ & 32.7 & $9 \cdot 5$ & $1 \cdot 8$ & $1 \cdot 3$ & $2 \cdot 2$ \\
\hline & & Wheat & 0.79 & 0.91 & 1.6 & $30 \cdot 6$ & 1.8 & $29 \cdot 0$ & $2 \cdot 0$ & 1.6 & $0 \cdot 5$ & 1.7 \\
\hline & & Sorghum & 1.00 & 0.99 & $1 \cdot 1$ & $39 \cdot 1$ & 9.7 & $38 \cdot 9$ & $10 \cdot 8$ & $1 \cdot 1$ & $0 \cdot 8$ & 1.4 \\
\hline & & Soybean & 0.96 & 0.99 & $3 \cdot 1$ & $36 \cdot 7$ & $7 \cdot 8$ & 33.6 & $9 \cdot 0$ & $3 \cdot 4$ & 0.7 & $3 \cdot 4$ \\
\hline \multirow[t]{4}{*}{ Clay Center, NE } & \multirow[t]{4}{*}{1987} & Corn & 0.91 & 0.91 & $4 \cdot 1$ & $54 \cdot 4$ & 8.4 & $58 \cdot 5$ & $8 \cdot 2$ & $4 \cdot 1$ & $2 \cdot 3$ & $4 \cdot 7$ \\
\hline & & Wheat & 0.78 & 0.40 & $3 \cdot 8$ & $61 \cdot 2$ & $4 \cdot 6$ & $59 \cdot 5$ & $5 \cdot 6$ & $3 \cdot 1$ & 3.4 & $4 \cdot 6$ \\
\hline & & Sorghum & 0.98 & 0.98 & 1.7 & $61 \cdot 0$ & $8 \cdot 3$ & $59 \cdot 6$ & $9 \cdot 5$ & $1 \cdot 8$ & $1 \cdot 0$ & $2 \cdot 0$ \\
\hline & & Soybean & $0 \cdot 96$ & $0 \cdot 96$ & $2 \cdot 0$ & $62 \cdot 5$ & $6 \cdot 7$ & $64 \cdot 5$ & $7 \cdot 0$ & $2 \cdot 1$ & $1 \cdot 3$ & $2 \cdot 4$ \\
\hline \multirow[t]{3}{*}{ Concord, NE } & \multirow[t]{3}{*}{1987} & Corn & 0.92 & 0.74 & $2 \cdot 0$ & $29 \cdot 5$ & $5 \cdot 4$ & $29 \cdot 8$ & $4 \cdot 6$ & $0 \cdot 3$ & $2 \cdot 7$ & $2 \cdot 7$ \\
\hline & & Sorghum & 0.75 & 0.67 & $4 \cdot 6$ & $28 \cdot 8$ & $6 \cdot 5$ & $24 \cdot 2$ & $5 \cdot 4$ & $4 \cdot 6$ & $3 \cdot 5$ & $5 \cdot 8$ \\
\hline & & Soybean & $0 \cdot 70$ & 0.78 & $7 \cdot 9$ & $40 \cdot 6$ & $6 \cdot 7$ & $32 \cdot 7$ & $7 \cdot 5$ & $8 \cdot 0$ & $3 \cdot 0$ & $8 \cdot 6$ \\
\hline \multirow[t]{2}{*}{ Mead, NE } & \multirow[t]{2}{*}{1986} & Wheat & 0.79 & 0.98 & $2 \cdot 9$ & $45 \cdot 4$ & $3 \cdot 1$ & $42 \cdot 5$ & $6 \cdot 2$ & $4 \cdot 0$ & 0.4 & $4 \cdot 0$ \\
\hline & & Soybean & 0.79 & 0.71 & $2 \cdot 7$ & $58 \cdot 0$ & $3 \cdot 6$ & $55 \cdot 3$ & $4 \cdot 3$ & $3 \cdot 0$ & 1.7 & $3 \cdot 4$ \\
\hline Brookings, SD & 1987 & Corn & 0.95 & 0.93 & $1 \cdot 1$ & $24 \cdot 4$ & $3 \cdot 3$ & $25 \cdot 1$ & $4 \cdot 3$ & $1 \cdot 2$ & 0.7 & 1.4 \\
\hline Chamberlin, SD & 1987 & Corn & 0.96 & 0.95 & 1.0 & $29 \cdot 1$ & $3 \cdot 5$ & $30 \cdot 1$ & $4 \cdot 0$ & $1 \cdot 2$ & 0.7 & 1.4 \\
\hline Wheatland, WY & 1986 & Wheat & $0 \cdot 84$ & 0.68 & $1 \cdot 0$ & $22 \cdot 6$ & $1 \cdot 5$ & $23 \cdot 4$ & 1.7 & $1 \cdot 0$ & $0 \cdot 8$ & $1 \cdot 3$ \\
\hline Sidney, NE & 1987 & Wheat & $0 \cdot 86$ & 0.99 & $3 \cdot 3$ & $28 \cdot 4$ & $5 \cdot 4$ & $31 \cdot 7$ & $4 \cdot 1$ & $3 \cdot 5$ & $0 \cdot 6$ & $3 \cdot 6$ \\
\hline Chugwater, WY & 1987 & Grass & $0 \cdot 86$ & 0.77 & $1 \cdot 2$ & $26 \cdot 5$ & $1 \cdot 5$ & $26 \cdot 1$ & $2 \cdot 6$ & $1 \cdot 3$ & 0.7 & $1 \cdot 5$ \\
\hline
\end{tabular}

MAE, mean absolute error; $P$, predicted soil moisture; $O$, observed soil moisture; $\sigma_{\mathrm{p}}$, variance of predicted soil moisture; $\sigma_{\mathrm{o}}$, Variance of observed soil moisture; RMSE, root mean square error; $E_{\mathrm{s}}$, systematic component of RMSE; $E_{\mathrm{u}}$, unsytematic component of RMSE.

Table III. Model performance at various depths under corn land use at North Platte, NE (Source: Robinson and Hubbard, 1990)

\begin{tabular}{|c|c|c|c|c|c|c|c|c|c|c|}
\hline Soil layer $(\mathrm{mm})$ & $d$ index & $r^{2}$ & MAE (cm) & $P(\mathrm{~cm})$ & $\sigma_{\mathrm{p}}\left(\mathrm{cm}^{2}\right)$ & $O(\mathrm{~cm})$ & $\sigma_{\mathrm{o}}\left(\mathrm{cm}^{2}\right)$ & $E_{\mathrm{s}}(\mathrm{cm})$ & $E_{\mathrm{u}}(\mathrm{cm})$ & $\operatorname{RMSE}(\mathrm{cm})$ \\
\hline $0-300$ & 0.97 & 0.94 & $0 \cdot 5$ & $5 \cdot 6$ & 1.8 & $6 \cdot 0$ & $1 \cdot 8$ & 0.4 & 0.4 & 0.6 \\
\hline $300-600$ & 0.95 & 0.97 & 0.7 & 5.6 & $2 \cdot 1$ & $6 \cdot 2$ & 1.7 & 0.7 & 0.4 & 0.8 \\
\hline $600-900$ & 0.99 & 0.98 & 0.4 & $5 \cdot 6$ & $2 \cdot 1$ & $5 \cdot 6$ & 1.7 & $0 \cdot 3$ & $0 \cdot 3$ & 0.4 \\
\hline $900-1200$ & 0.98 & 0.96 & 0.4 & $6 \cdot 1$ & $1 \cdot 8$ & $5 \cdot 7$ & $2 \cdot 0$ & 0.4 & 0.4 & 0.6 \\
\hline $1200-1500$ & 0.92 & 0.92 & 0.9 & $6 \cdot 2$ & 1.5 & $5 \cdot 5$ & 1.9 & 0.8 & 0.4 & 0.9 \\
\hline $1500-1800$ & 0.88 & 0.95 & $0 \cdot 8$ & $6 \cdot 2$ & $1 \cdot 1$ & $5 \cdot 6$ & 1.7 & $0 \cdot 9$ & $0 \cdot 3$ & 0.9 \\
\hline
\end{tabular}

MAE, mean absolute error; $P$, predicted soil moisture; $O$, observed soil moisture; $\sigma_{\mathrm{p}}$, variance of predicted soil moisture; $\sigma_{\mathrm{o}}$, Variance of observed soil moisture; RMSE, root mean square error; $E_{\mathrm{s}}$, systematic component of RMSE; $E_{\mathrm{u}}$, unsytematic component of RMSE.

of 20 cases (Table II). All, except one, $r^{2}$ estimates are between 0.99 and 0.67 . The observed and predicted SM values range between 23.4 and 64.5 and 22.6 and 62.5 $\mathrm{cm}$, respectively (Table II). In addition, observed and predicted variances for SM values range between 1.7 and 10.8 and 1.5 and $10.2 \mathrm{~cm}$, respectively. Clearly, high $d$ index and ' $r$ ' ' estimates suggest a high degree of agreement between observed and predicted SM values and agreement between their variances clearly indicates that the model performance is satisfactory for heterogeneous land uses and soil physical properties. It is also found that phase and amplitude of modelled and measured SM are in good agreement.

The Robinson-Hubbard model was evaluated for its estimation of SM at various depths in the root zone. Assessment for North Platte, NE shows that the $d$ index and $r^{2}$ estimates for observed and modelled SM for six layers ranged between 0.88 and 0.98 and 0.92 and 0.98 , respectively (Table III). Moreover, observed and predicted SM for these six layers of root zone ranged between 5.5 and $6.2 \mathrm{~cm}$ and 5.6 and $6.2 \mathrm{~cm}$, respectively
(Table III). The variance of the observed and predicted SM for these layers ranged between 1.7 and 2.0 and 1.1 and $2.1 \mathrm{~cm}$, respectively. Thus, the Robinson-Hubbard model estimates SM satisfactorily for various soil layers of the root zone.

Camargo (1993) and Camargo et al. (1994) conducted an additional data collection and model evaluation campaign. Eight irrigation treatments were applied in a split plot design for sorghum at Mead, NE during the 1990 and 1991 growing season. This design was developed based on plant phenological progress and under this scheme irrigation was applied or withheld in all combinations for the three growth stages. The depletion of plant available SM below $50 \%$ of field capacity in the $0-90 \mathrm{~cm}$ layer of the fully irrigated plot would trigger irrigation for all plots where water was not being withheld. The $d$ index and $r^{2}$ values range from 0.78 to 0.96 and 0.64 to 0.93 , respectively. However, in most of the cases $d$ index and $r^{2}$ values for model evaluation remained above 0.90 and $0 \cdot 80$. A total of 16 irrigation treatment designs $(8+8$ treatment design over 2 years) were developed for this 
validation. Of these the $d$-index exceeded 0.90 nine times and 0.8014 times. Moreover, $r^{2}$ reached over 0.80 on 12 occasions under the 16 treatments. The performance of the model in simulating SM in the five soil layers was satisfactory, which is indicated by the $d$ index and $r^{2}$ estimates of 0.95 and 0.96 , respectively. Recent applications also show that the model is simulating soil water satisfactorily (Mahmood et al., 2001; Mahmood and Hubbard, 2002, 2003, 2004).

Detailed quantitative evaluation suggests that the Robinson-Hubbard model performance is superior to existing models, including the Crawford et al. (2000) model, and to a number of LSSs used in GSWP, AMIP and PILPS. In many cases, evaluation activities were limited for these models and were not evaluated for multiple land uses, root zone depths, locations, years and soils and under significantly variable hydroclimatic conditions. For example, Crawford et al. (2000) have used 1 month of data from one land use for their model validation and found that $r^{2}$ between observed and simulated SM for 25,60 and $75 \mathrm{~cm}$ depth ranged between 0.27 and 0.40. Robinson and Hubbard (1990) recorded $r^{2}$ between 0.94 and 0.98 for comparable depth ranges and Camargo et al. (1994) found $r^{2}$ values ranged between 0.73 and 0.96. Crawford et al. (2000) reported that simulation of $\mathrm{SM}$ at deeper layers by their model was not satisfactory. Table III demonstrates that the Robinson-Hubbard model performance is satisfactory for deeper layers.

The Robinson-Hubbard model is applied at Mead, Clay Center and McCook (Figure 1) in Nebraska and they follow an east to west gradient from moist (Mead) to very dry (McCook) conditions. In other words, they represent varying land use and moisture regimes. Three applications of the Robinson-Hubbard model per site (three types of land use by one soil type) were completed. The design of these applications helped to determine to what extent the relationship between near-surface SM and SM at various depths of the root zone changes under different land uses and hydroclimatic regimes. Daily weather data for the Robinson-Hubbard model simulations were provided by the automated weather stations at the study sites, which are maintained and operated by the High Plains Regional Climate Center (HPRCC). The HPRCC also provided site-specific soil input data, which includes bulk density, soil texture, wilting point, field capacity and saturation point for each soil layer (Tables IV and V). In the following discussion individual layer SM is presented as volumetric water content $\left(\mathrm{mm}^{3} \mathrm{~mm}^{-3}\right)$ and plant available root zone water (SM) is presented as water depth.

Table IV. Distribution of clay, sand, and silt at three locations in Nebraska (Mahmood and Hubbard, 2004)

\begin{tabular}{lccc}
\hline Location & Clay $(\%)$ & Sand (\%) & Silt (\%) \\
\hline McCook & 15 & 20 & 65 \\
Clay Center & 30 & 10 & 60 \\
Mead & 65 & 5 & 30 \\
\hline
\end{tabular}

Table V. Selected hydrological properties (in volumetric water content) of soils at various depths of three sites in NE (Mahmood and Hubbard, 2004)

\begin{tabular}{|c|c|c|c|c|}
\hline Location & $\begin{array}{l}\text { Depth } \\
(\mathrm{cm})\end{array}$ & $\begin{array}{l}\text { Saturation } \\
\text { point }\end{array}$ & $\begin{array}{c}\text { Field } \\
\text { capacity }\end{array}$ & $\begin{array}{l}\text { Wilting } \\
\text { point }\end{array}$ \\
\hline \multirow[t]{5}{*}{ McCook } & $0-2 \cdot 5$ & 0.46 & $0 \cdot 36$ & $0 \cdot 22$ \\
\hline & $2 \cdot 5-30 \cdot 5$ & 0.52 & 0.36 & 0.22 \\
\hline & $30 \cdot 5-61$ & 0.48 & 0.36 & $0 \cdot 22$ \\
\hline & $61-91 \cdot 5$ & 0.42 & $0 \cdot 36$ & $0 \cdot 22$ \\
\hline & $91 \cdot 5-122$ & $0 \cdot 46$ & $0 \cdot 36$ & $0 \cdot 22$ \\
\hline \multirow[t]{5}{*}{ Clay Center } & $0-2 \cdot 5$ & 0.46 & 0.32 & $0 \cdot 12$ \\
\hline & $2 \cdot 5-30 \cdot 5$ & $0 \cdot 52$ & $0 \cdot 32$ & $0 \cdot 16$ \\
\hline & $30 \cdot 5-61$ & $0 \cdot 48$ & 0.33 & $0 \cdot 17$ \\
\hline & $61-91 \cdot 5$ & 0.42 & 0.33 & $0 \cdot 14$ \\
\hline & $91 \cdot 5-122$ & 0.46 & 0.34 & $0 \cdot 14$ \\
\hline \multirow[t]{5}{*}{ Mead } & $0-2 \cdot 5$ & 0.46 & $0 \cdot 36$ & $0 \cdot 18$ \\
\hline & $2 \cdot 5-30 \cdot 5$ & 0.55 & $0 \cdot 36$ & $0 \cdot 18$ \\
\hline & $30 \cdot 5-61$ & $0 \cdot 65$ & 0.40 & $0 \cdot 20$ \\
\hline & $61-91 \cdot 5$ & 0.65 & 0.40 & $0 \cdot 20$ \\
\hline & $91 \cdot 5-122$ & 0.59 & 0.42 & $0 \cdot 20$ \\
\hline
\end{tabular}

\section{ROBINSON-HUBBARD MODEL APPLICATIONS AND TEMPORAL DISTRIBUTION OF PLANT AVAILABLE ROOT ZONE SM}

The Robinson-Hubbard model was run for irrigated corn, rainfed corn and rainfed grass from 1982 through to 1999 for each of the locations. Model runs begin on 5 May and represent the beginning of the growing season. Each run ended on 4 May of the subsequent year. To capture real world conditions, the soil water balance from the end of each annual simulation was carried over to the next simulation. Phenological development of grass, rainfed and irrigated corn are different for each. As a result, three separate accumulated growing degreedays (GDD) were included during the model simulations to accurately determine phenological progress of these plants (Table VI). This is essential because phenological development significantly influences the plant-water use and thus root zone soil water. We have used different GDDs for each crop/land use. However, these GDDs remained unchanged for all locations in order to understand hydroclimatic influences. Irrigation in the model was triggered when root zone soil water fell below the mid-point between field capacity and wilting point. Since plant growth and phenological development are dependent on thermal conditions (captured by GDD), interannual variations in temperature affected length-of-time to reach maturity.

At the westernmost site (McCook), on average, the amount of plant available soil water throughout the growing season is relatively higher for irrigated corn compared with rainfed corn and rainfed grass (Figure 2ac). Clay Center also shows a similar SM distribution for irrigated corn. Supply of water by irrigation to fulfill plant water requirements results in higher plant available SM for irrigated corn. Season-wide distribution suggests a significant decrease in plant available SM with plant growth and associated increase in consumption. This depletion is most widespread under rainfed corn 
Table VI. Assigned accumulated growing degree days for three land uses

\begin{tabular}{lccc}
\hline Land use & $\begin{array}{c}\text { Base } \\
\text { temperature } \\
\left({ }^{\circ} \mathrm{C}\right)\end{array}$ & $\begin{array}{c}\text { Cut-off (high) } \\
\text { temperature } \\
\left({ }^{\circ} \mathrm{C}\right)\end{array}$ & $\begin{array}{c}\text { Accumulated } \\
\text { growing degree } \\
\text { days at } \\
\text { maturity }\left({ }^{\circ} \mathrm{C}\right)\end{array}$ \\
\hline Irrigated corn & 10 & 30 & 1538 \\
Rainfed corn & 10 & 30 & 1204 \\
Grass & 4 & 25 & 1649 \\
\hline
\end{tabular}

(Figure 2b). For example, at McCook mean lowest plant available SM for irrigated and rainfed corn, and grass is 9,4 and $6 \mathrm{~cm}$, respectively (Figures $2 \mathrm{a}-\mathrm{c}$ ). Grass requires less SM to fulfill its physiological demand and this results in higher plant available SM under this land use compared with rainfed corn. At Mead, plant available SM also decreases with the progression of plant growth (Figures $3 a-c)$. Due to its sub-humid location, plant available SM is higher for all three land uses at Mead compared with McCook and Clay Center. For example, the mean daily plant available SM for irrigated and rainfed corn and grass is 12,14 and $17 \mathrm{~cm}$, respectively. Here, the lowest mean daily plant available SM is under irrigated corn, not rainfed corn. Several factors need to be considered to explain this outcome. First, due to the selected GDD (Table VI), length of growing season for irrigated corn is longer; second, natural plant available SM is higher due to the moist subhumid environment; and third, the water holding capacity of the soil is higher at this location. The latter allowed soils to hold SM for a longer period of time and thus plants mined stored water first before requiring irrigation. Due to the shorter growing season and greater availability of water at Mead, rainfed corn did not use as much water.

\section{SOIL MOISTURE AT VARIOUS DEPTHS OF THE ROOT ZONE}

Under irrigated and rainfed corn and grass land use, mean daily volumetric water content in almost all layers is higher at Mead compared with the other two locations (Tables VII-IX). As noted above, hydroclimatologically Mead is a relatively moist site compared with McCook and Clay Center. At all sites and under these three land

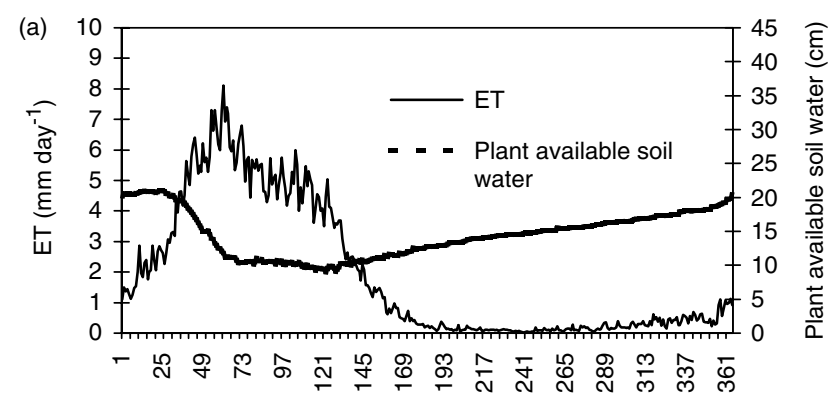

Day (May 5, XX01 - May 4, XX02)
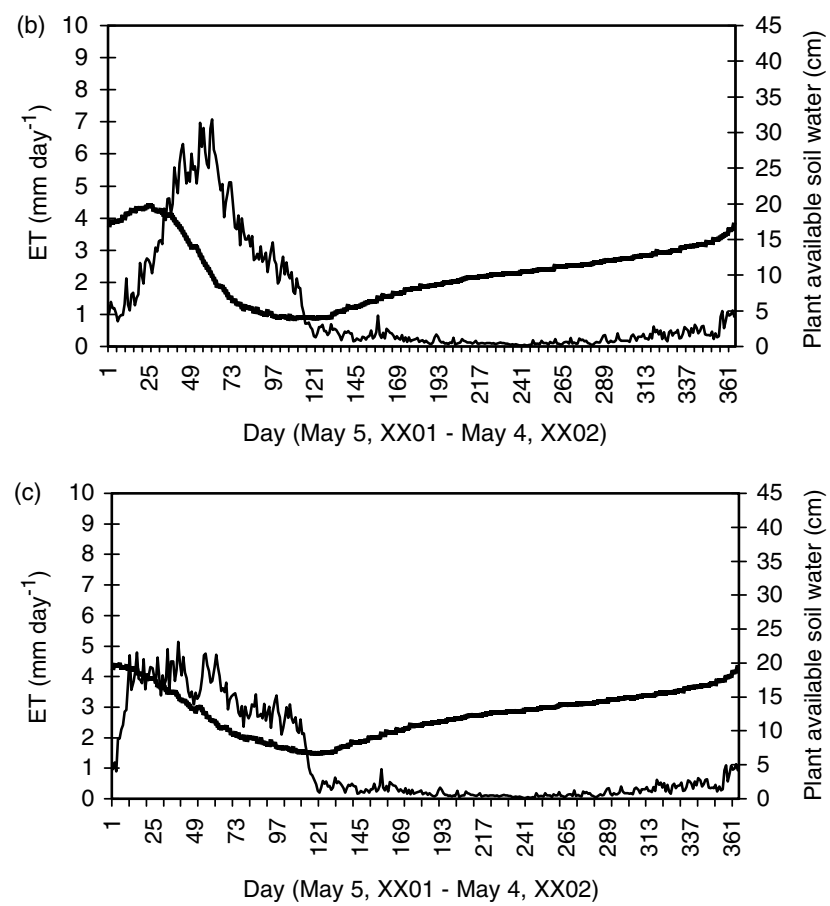

Figure 2. Mean (1982-1999) daily ET and plant available soil water for three land uses at McCook, Nebraska: (a) irrigated corn, (b) rainfed corn and (c) grass. First simulation starts on 5 May 1982 and ends on 4 May 1983. This process continued through to 1998-1999. Soil moisture balance of a year carried over to subsequent years (Source: Mahmood and Hubbard, 2002)

uses the second layer of the soil profile is relatively moist. The top layer of the soil loses moisture more quickly largely due to evaporation. Relatively less moisture reaches the lower layers of the soil profiles after drainage to the second and third layers. Soil moisture at the fourth

Table VII. Average soil moisture (volumetric water content) under three land uses in Nebraska for the period 1982-1999

\begin{tabular}{|c|c|c|c|c|c|c|}
\hline Station & Parameters & $\begin{array}{l}\text { Layer } 10-2 \cdot 5 \\
(\mathrm{~cm})\end{array}$ & $\begin{array}{c}\text { Layer } 22 \cdot 5-30 \cdot 5 \\
(\mathrm{~cm})\end{array}$ & 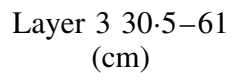 & $\begin{array}{l}\text { Layer } 461-91 \cdot 5 \\
(\mathrm{~cm})\end{array}$ & $\begin{array}{c}\text { Layer } 591 \cdot 5-122 \\
(\mathrm{~cm})\end{array}$ \\
\hline \multirow[t]{3}{*}{ McCook } & Irrigated corn & $0 \cdot 26$ & $0 \cdot 33$ & $0 \cdot 26$ & $0 \cdot 18$ & $0 \cdot 17$ \\
\hline & Rainfed corn & $0 \cdot 24$ & 0.29 & $0 \cdot 21$ & $0 \cdot 16$ & $0 \cdot 15$ \\
\hline & Grass & $0 \cdot 24$ & $0 \cdot 27$ & $0 \cdot 20$ & $0 \cdot 18$ & $0 \cdot 23$ \\
\hline \multirow{3}{*}{ Clay Center } & Irrigated corn & $0 \cdot 31$ & $0 \cdot 37$ & $0 \cdot 32$ & $0 \cdot 24$ & 0.25 \\
\hline & Rainfed corn & $0 \cdot 32$ & $0 \cdot 37$ & $0 \cdot 32$ & $0 \cdot 26$ & 0.28 \\
\hline & Grass & $0 \cdot 31$ & $0 \cdot 35$ & $0 \cdot 32$ & $0 \cdot 28$ & $0 \cdot 32$ \\
\hline \multirow[t]{3}{*}{ Mead } & Irrigated corn & 0.46 & 0.53 & $0 \cdot 38$ & $0 \cdot 27$ & $0 \cdot 16$ \\
\hline & Rainfed corn & 0.46 & 0.53 & 0.41 & $0 \cdot 30$ & $0 \cdot 24$ \\
\hline & Grass & $0 \cdot 45$ & 0.47 & $0 \cdot 36$ & $0 \cdot 34$ & $0 \cdot 36$ \\
\hline
\end{tabular}


Table VIII. Relationship between near-surface (top $2.5 \mathrm{~cm}$ ) and plant available root zone SM

\begin{tabular}{llccc}
\hline Location & \multicolumn{1}{c}{ Statistic } & Grass & Rainfed corn & Irrigated corn \\
\hline McCook & Correlation (0-day lag) & $0 \cdot 23$ & $0 \cdot 29$ & $0 \cdot 02$ \\
& Cross-correlation* & $0 \cdot 40(75)$ & $0 \cdot 32(18)$ & $0 \cdot 22(119)$ \\
Clay Center & Correlation (0-day lag) & $0 \cdot 33$ & $0 \cdot 32$ & $0 \cdot 17$ \\
& Cross-correlation* & $0.48(53)$ & $0.41(52)$ & $0 \cdot 33(66)$ \\
Mead & Correlation (0-day lag) & $0 \cdot 19$ & $0 \cdot 27$ & $0 \cdot 16$ \\
& Cross-correlation* & $0 \cdot 39(56)$ & $0 \cdot 37(38)$ & $0 \cdot 34(57)$ \\
\hline
\end{tabular}

* Number of days lag in parentheses.
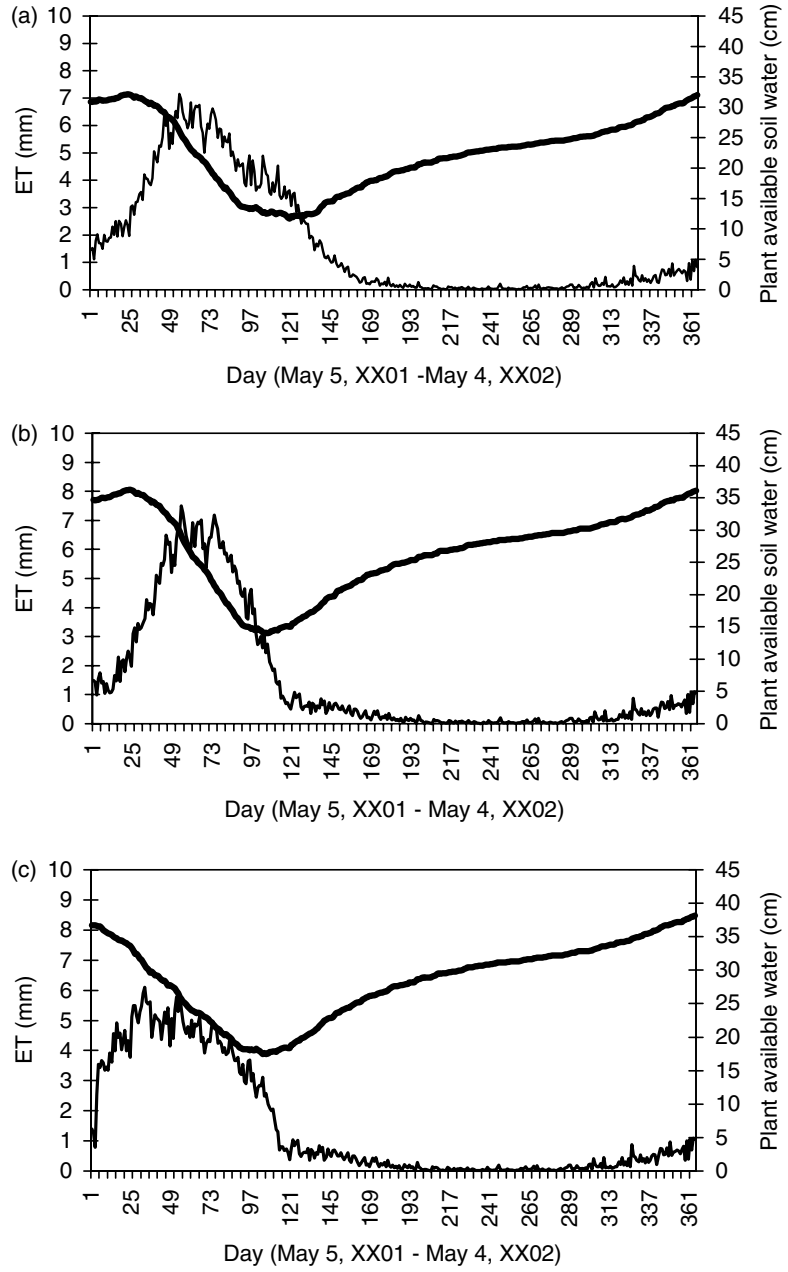

Figure 3. Mean (1982-1999) daily ET and plant available soil water for three land uses at Mead, Nebraska: (a) irrigated corn, (b) rainfed corn and (c) grass. First simulation starts on 5 May 1982 and ends on 4 May 1983. This process continued through to 1998-1999. Soil moisture balance of a year carried over to subsequent years (Source: Mahmood and Hubbard, 2002)

and fifth layers for grass is higher compared with rainfed and irrigated corn at all locations (Table VII). This is due to the fact that grass does not extract as much moisture from these layers compared with rainfed and irrigated corn. Compared with rainfed corn, slightly lower SM in the top three layers under grass land use also suggests relatively higher use of water from these layers.

At McCook mean daily SM estimates for the top soil layer (a $2.5 \mathrm{~cm}$ layer at the surface) under irrigated corn (Figure 4a) show relatively more fluctuation. This layer responds quickly under a precipitation event or during a dry spell. Hence, the lowest and the highest volumetric water content for the top soil layer is lower compared with the second layer $(2 \cdot 5-30.5 \mathrm{~cm})$ (Figure $4 \mathrm{~b})$. It is found that the fluctuation in soil water content in the top soil layer is higher during the plant growing period, whereas the second layer of the soil shows far less fluctuation. Compared with the second layer, soil water depletes more rapidly in the third layer $(30 \cdot 5-61 \mathrm{~cm})$, followed by fourth $(61-91.5 \mathrm{~cm})$ and fifth layers $(91 \cdot 5-122 \mathrm{~cm})$ (Figures $4 \mathrm{~b}-\mathrm{e}$ ).

Soil water content for rainfed corn in the top soil layer at McCook experiences fluctuations that resemble conditions under irrigated corn (compare Figures 5a and 4a). The study finds that volumetric soil water content for rainfed corn land use remain below 0.25 for a much longer time period (113 days) compared with irrigated corn $(<15$ days). On the other hand, soil water content for grass land use depletes from the second layer more rapidly compared with rainfed corn (Figure 5f). Water consumption behaviour related to plant growth and crop specific phenology resulted in these differences. Under grass land use, soil water content in the second layer remains below 0.25 for a longer time period (124 days) compared with rainfed corn. Soil water in the fourth and fifth layers for grass never reaches the lows encountered under rainfed corn (Figure 5h) due to the fact that grass does not use as much SM as rainfed corn. Mean daily SM patterns at Clay Center for all three land uses bear a resemblance to those at McCook. Due to the relatively moist hydroclimatic condition, however, soil water content at Clay Center never depletes to the level of McCook (Figures 6a-e; rainfed corn is shown as an example).

\section{RELATIONSHIP BETWEEN NEAR-SURFACE AND PLANT AVAILABLE ROOT ZONE SM}

As noted in the introduction, we are interested in the climate-scale correlation between near-surface SM $(0-2.5 \mathrm{~cm})$ to plant available $\mathrm{SM}$ in the root zone, the strength of these correlations and the variation of these correlations under different land uses and soils. Here we attempt to answer these questions. This study performed two sets of assessments for this purpose. These included: (i) correlation and cross-correlation between top layer $(0-2.5 \mathrm{~cm})$ and plant available root zone SM of all land 
Table IX. Relationship between near-surface SM and SM at various depths. See Table VI for depths of the layers

\begin{tabular}{|c|c|c|c|c|c|c|}
\hline Location & Land use & Statistic & $\begin{array}{l}\text { Layer } 1 \\
\text { versus } 2\end{array}$ & $\begin{array}{c}\text { Layer } 1 \\
\text { versus } 3\end{array}$ & $\begin{array}{l}\text { Layer } 1 \\
\text { versus } 4\end{array}$ & $\begin{array}{l}\text { Layer } 1 \\
\text { versus } 5\end{array}$ \\
\hline \multirow[t]{6}{*}{ McCook } & \multirow[t]{2}{*}{ Grass } & Correlation & 0.49 & 0.09 & $-0 \cdot 14$ & $-0 \cdot 15$ \\
\hline & & Cross-correlation* & $0 \cdot 50(1)$ & $0 \cdot 39(82)$ & $0 \cdot 36(135)$ & $0 \cdot 24(191)$ \\
\hline & \multirow[t]{2}{*}{ Rainfed corn } & Correlation & 0.50 & $0 \cdot 20$ & 0.02 & -0.04 \\
\hline & & Cross-correlation* & $0.51(1)$ & $0.29(49)$ & $0.29(125)$ & $0 \cdot 20(141)$ \\
\hline & \multirow[t]{2}{*}{ Irrigated corn } & Correlation & $0 \cdot 51$ & 0.04 & -0.07 & -0.04 \\
\hline & & Cross-correlation* & $0.47(1)$ & $0 \cdot 21(85)$ & $0 \cdot 25$ (117) & $0 \cdot 21(144)$ \\
\hline \multirow[t]{6}{*}{ Clay Center } & \multirow[t]{2}{*}{ Grass } & Correlation & 0.67 & $0 \cdot 34$ & $0 \cdot 22$ & 0.19 \\
\hline & & Cross-correlation* & $0.68(1)$ & $0 \cdot 57(57)$ & $0.52(81)$ & $0.46(91)$ \\
\hline & \multirow[t]{2}{*}{ Rainfed corn } & Correlation & 0.69 & $0 \cdot 36$ & $0 \cdot 19$ & $0 \cdot 14$ \\
\hline & & Cross-correlation* & $0.69(1)$ & $0.43(27)$ & $0 \cdot 37(61)$ & $0 \cdot 36(81)$ \\
\hline & \multirow[t]{2}{*}{ Irrigated Corn } & Correlation & $0 \cdot 56$ & $0 \cdot 21$ & 0.02 & $-0 \cdot 11$ \\
\hline & & Cross-correlation* & Decreases with lag & $0 \cdot 34(62)$ & $0 \cdot 33(75)$ & $0 \cdot 29(115)$ \\
\hline \multirow[t]{6}{*}{ Mead } & \multirow[t]{2}{*}{ Grass } & Correlation & 0.54 & $0 \cdot 01$ & -0.13 & $-0 \cdot 19$ \\
\hline & & Cross-correlation* & $0 \cdot 60(20)$ & $0.42(91)$ & $0 \cdot 19(118)$ & Decreases with lag \\
\hline & \multirow[t]{2}{*}{ Rainfed Corn } & Correlation & 0.59 & $0 \cdot 25$ & 0.03 & $-0 \cdot 10$ \\
\hline & & Cross-correlation* & $0.60(4)$ & $0.42(47)$ & $0 \cdot 26(90)$ & Decreases with lag \\
\hline & \multirow[t]{2}{*}{ Irrigated Corn } & Correlation & 0.42 & 0.09 & -0.04 & $-0 \cdot 12$ \\
\hline & & Cross-correlation* & $0.44(6)$ & $0.34(67)$ & $0.23(98)$ & Decreases with lag \\
\hline
\end{tabular}

${ }^{*}$ Number of days lag in parentheses.

(a)

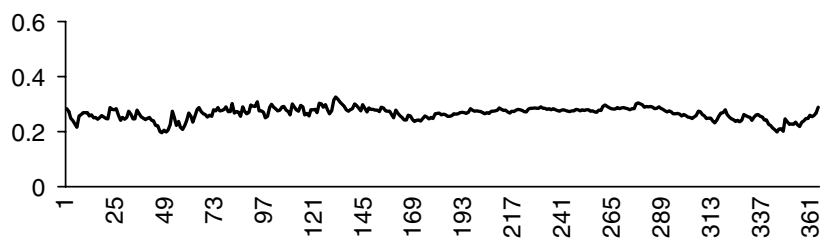

(c)

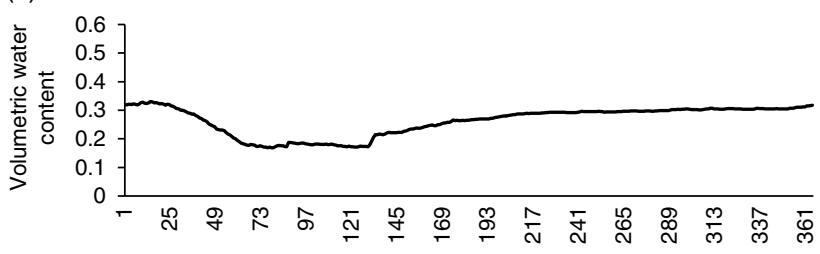

(b)

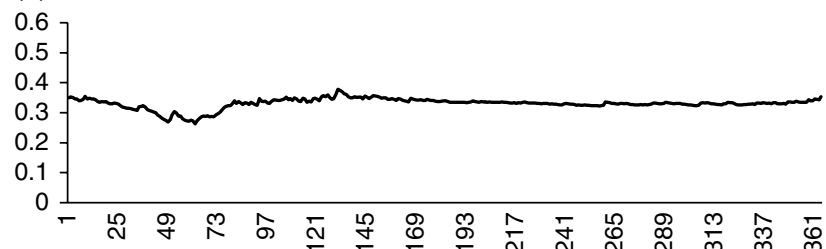

(d)

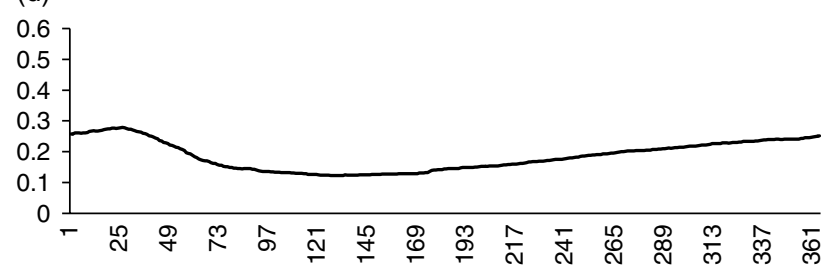

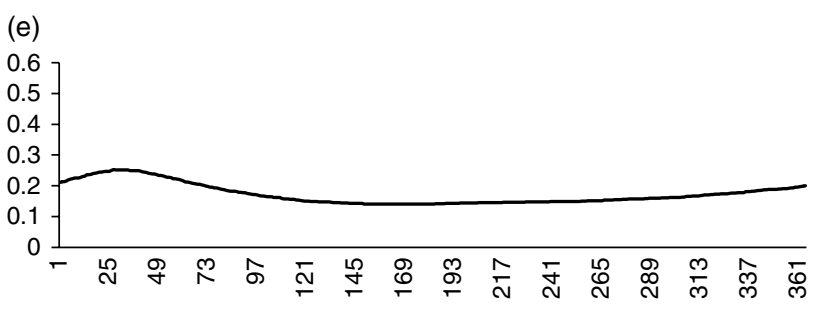

Day (May 5, XX01 - May 4, XX02)

Figure 4. Mean daily volumetric soil moisture content at various depths for irrigated corn at McCook, NE: (a) top layer, (b) layer 2, (c) layer 3, (d) layer 4 and (e) layer 5. Day 1 is 5 May (Source: Mahmood and Hubbard, 2004)

uses at all three locations, and (ii) correlation and crosscorrelation between top layer and plant available root zone SM for the growing season of each year for all land uses at all locations. Cross-correlation allows assessment of time-lag relationships. The length of the time series for all locations and land uses is from 5 May 1982 through to 4 May 1999. These analyses provided the opportunity to determine the strength of the correlation, the lag for attaining maximum correlation, and how these correlation and lags vary by the year. Correlation for zero lag or same day correlation is also calculated. The SM variation is highest during the growing season and therefore a second set of analyses in this section focused on this season. In addition, year-to-year variations allow us to examine interannual climatic variations and their impacts on SM.

It is found that correlations between the top soil layer and plant available root zone SM for grass, rainfed corn 

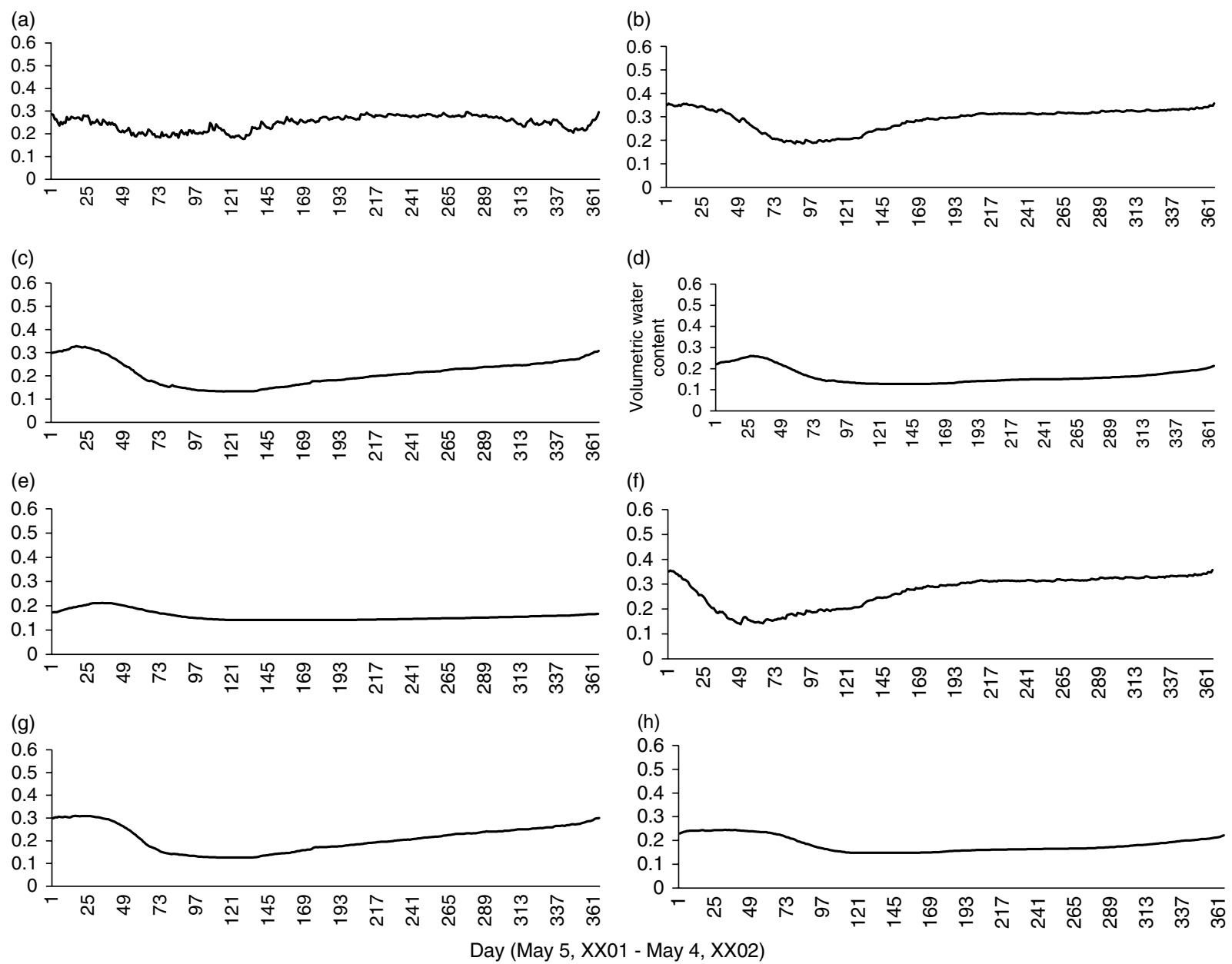

Figure 5. Mean daily volumetric soil moisture content at various depths for rainfed corn at McCook, NE: (a) top layer, (b) layer 2, (c) layer 3 , (d) layer 4 and (e) layer 5; and for grass: (f)) layer 2, (g) layer 3, (h) layer 4. Day 1 is 5 May (Source: Mahmood and Hubbard, 2004)
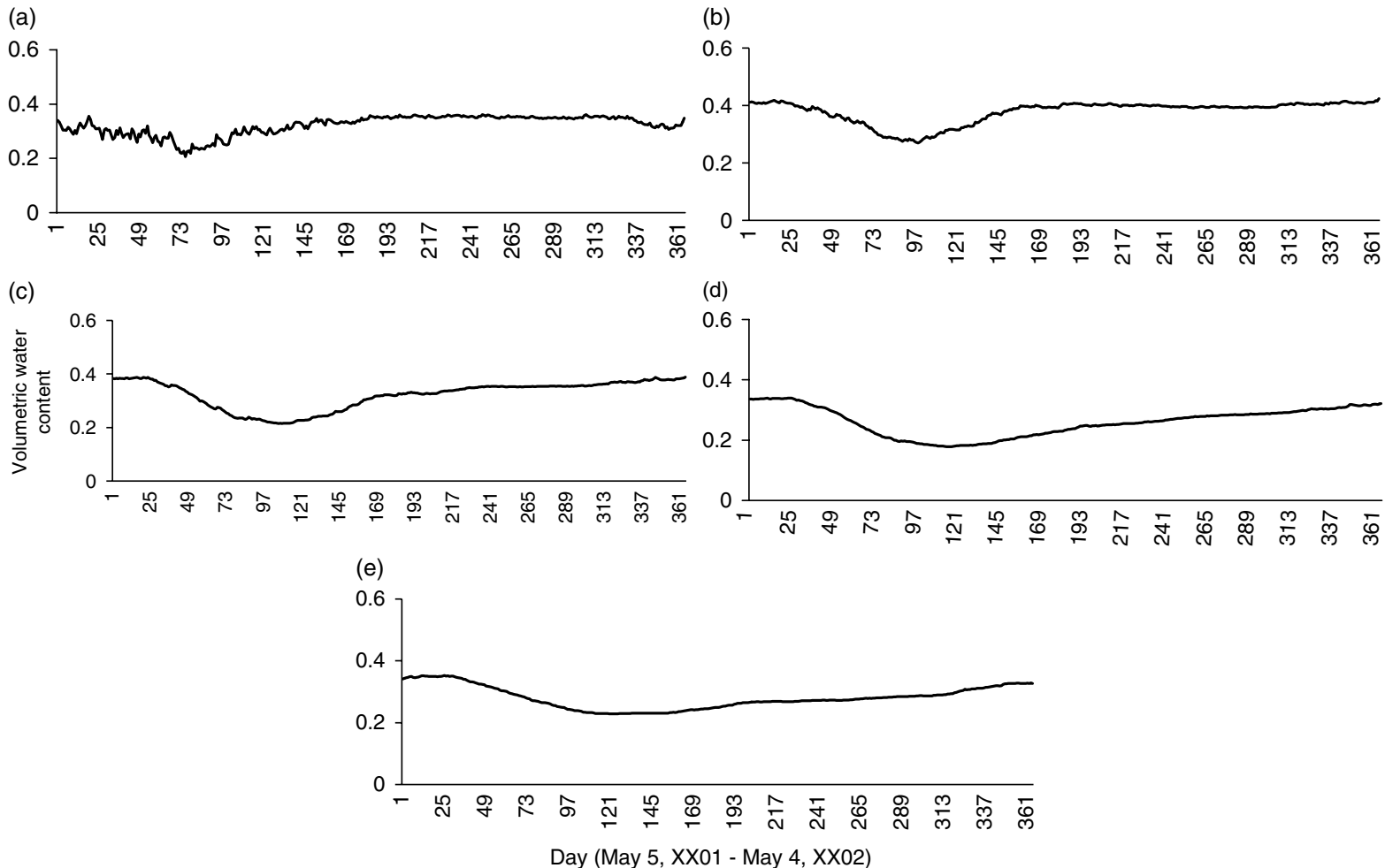

Figure 6. Mean daily volumetric soil moisture content at various depths for rainfed corn at Clay Center, NE: (a) top layer, (b) layer 2, (c) layer 3 , (d) layer 4 and (e) layer 5. Day 1 is 5 May (Source: Mahmood and Hubbard, 2004) 
and irrigated corn at McCook are 0.23, 0.29 and 0.02, respectively, at zero lag (Table VIII). The correlations for these land uses at zero lag at Clay Center are 0.33, 0.32 and $0 \cdot 17$, respectively and at Mead are $0 \cdot 19,0 \cdot 27$ and $0 \cdot 16$, respectively. It is clear that the correlation is quite weak for all cases. The results also indicate that at all locations the correlation is weakest for irrigated corn land use. To replicate real-world management practice, the model assumed application of water as soon as plant experienced water stress. Hence, the natural cycle of drying and recharging was interrupted, which resulted in lower correlation. The lowest correlation for irrigated corn at McCook provides further evidence of this. This is the driest location among the three and received the most frequent application of irrigated water to overcome stress, which resulted in the lowest correlation between the top layer and plant available root zone SM. Also, this correlation is much higher for grass and rainfed corn at McCook and, again, provides evidence that interruption of the natural cycle of SM variation resulted in lower correlation for irrigated corn. Clay Center reported the highest correlation for grass and rainfed corn. The soil at this location is predominantly silty clay (Table IV). Soils at McCook are silty and at Mead are clay (Table IV), and thus provide the potential for the lowest and highest water holding capacity, respectively. Hence, it can be said that both rapid drying and slow drainage can affect these correlations.

These outcomes of correlation are analogous to the results in the previous section, in a sense that SM at the top soil layer varies greater than the plant available root zone SM as a whole. Note, that the top layer of the soil interacts with the near-surface atmosphere at all timescales and therefore we see day-to-day fluctuations at this layer. On the other hand, the response of SM at the lower layers notably depends, among other things, on the plant and root growth and its water consumption behaviour in response to environmental forcing and physiological demand. This difference in SM modulation is partly responsible for the weak correlation. In a previous study, Mahmood and Hubbard (2004) showed differences in variability of SM at various depths of the root zone. They have also explained how varying plant and root growth and their water consumption behaviour results in such variations.

Since SM is modified by drainage of water (in and out of the layer) and by water use from the layer, further analyses were undertaken to establish time-lag relationships. The results suggest that at McCook, the highest crosscorrelation between top soil layer SM and plant available root zone SM for grass, rainfed corn and irrigated corn occurs at 75, 18 and 119 days lag, respectively, and these correlations are 0.40, 0.32 and 0.22 (Table VIII). At Clay Center these correlations occur at 53,52 and 66 days lag and the correlations are $0.48,0.41$ and 0.33 , respectively (Table VIII). Similar assessment for Mead suggests correlations of $0.39,0.37$ and 0.34 at 56, 38 and 57 days lag, respectively (Table VIII). As expected, the time-lag correlations are stronger than the zero lag correlations owing largely to the fact that time is required for drainage from the top layer to other layers. Irrigated land use, again, shows the lowest cross-correlation between top soil layer SM and plant available root zone SM. Time lags for these cross-correlations and for irrigated land use at all locations are 119, 66 and 57 days. These are the longest time lags among all land uses at all locations. Clay Center shows higher correlation for all land uses. In general, the time lags associated with higher cross-correlation and for all land uses and all locations vary from one month (38 days) to two and a half months (75 days) approximately.

\section{RELATIONSHIP BETWEEN NEAR-SURFACE AND ROOT ZONE SM AT VARIOUS DEPTHS}

To further understand the relationship between the top layer and root zone SM, Table IX presents correlation and cross-correlation of SM between top layer SM $(0-2.5 \mathrm{~cm})$ and that of the second $(2.5-30.5)$, third $(30.5-61 \mathrm{~cm})$, fourth $(61-91.5)$ and fifth $(91.5-122 \mathrm{~cm})$ layers, respectively. Same day or zero lag correlation is highest between the top and second layers for all land uses (Table IX). At McCook it ranges between 0.49 and 0.51 . Same day correlation between top and second layer SM ranges between 0.56 and 0.69 and 0.42 and 0.59 for Clay Center and Mead, respectively (Table IX). Similar to the previous section, these correlations decreased under irrigated conditions. Moreover, Clay Center demonstrated generally higher correlation between top and second layer SM for all land uses. There is a large reduction in strength of correlation between the top and third to fifth layers. Generally, the correlations between top and fifth layer SM for all land uses were weak and negative. It is encouraging that the association between the top and second layers is moderately strong at Clay Center and moderate at McCook and Mead. The results suggest the possibility of using the observed SM of the top layer as a predictor of SM up to a depth of $30 \mathrm{~cm}$.

This study also explored the strength of the crosscorrelation of SM between the top and other layers. For grass and rainfed corn land use, cross-correlation between the top and second layer at 1 day lag remains the same and slightly increased, respectively, at Clay Center. The cross-correlation of SM between these layers decreases with increasing lag. These associations for grass and rainfed corn land use at McCook also increase with 1 day lag. Subsequently, it declines with increasing time lag. At Mead, the strength of the cross-correlation between top and second layer SM increases to 0.60, 0.60 and 0.44 at 20, 4 and 6 days lag for grass, rainfed corn and irrigated corn land use, respectively.

Analyses of simulated data suggest a large decline in cross-correlation of SM between the top and the third to fifth layers (Table IX). Except for grass at Clay Center, cross-correlation of SM between the top and third layers ranges between 0.21 and 0.43 for all locations and for all land uses. The time lags for the cross-correlations 
range from 27 to 91 days. The strength of these crosscorrelations further declines and time lags further increase between the top and the fourth and fifth layers (Table IX).

\section{INTERANNUAL VARIATIONS IN THE RELATIONSHIP BETWEEN NEAR-SURFACE AND PLANT AVAILABLE SM}

Root zone SM amount and its distribution change from year-to-year in response to interannual variations in precipitation. Thus, it is critical to know year-to-year variations in correlation and cross-correlation between nearsurface and plant available root zone SM on an annual basis for different land uses under varying hydroclimatic regimes. Moreover, in our study region SM during the warm season (which coincides with growing season) plays a more active role in land surface and atmosphere interactions. Hence, to fulfill the objective we have used growing season time series for individual years from 1982 through to 1999. Table $X$ presents the results from this assessment. It is found that for grass, correlation (0 lag) varies from 0.63 to $-0.21,0.32$ to -0.16 and 0.63 to -0.37 for McCook, Clay Center and Mead. These correlations under grass land use are out of phase more frequently at Mead compared with any other location. Under rainfed corn land use correlations range from 0.72 to $-0.24,0.48$ to -0.18 and 0.62 to -0.14 at McCook, Clay Center and Mead, respectively. For irrigated land use, correlation between the top soil layer and plant available root zone SM ranges from 0.30 to $-0.32,0.40$ to -0.46 and 0.44 to -0.13 at McCook, Clay Center and Mead, respectively. As expected, assessment of seasonaland annual-scale correlation (0 day lag) between nearsurface and plant available root zone SM suggests that during warm months/growing season it can be notably higher in some years. This finding is applicable for all land uses at all three locations. It is also reported that at
McCook relatively higher correlation is associated with rainfed corn land use during a wet year (1993), whereas Mead suggests higher correlation for rainfed corn during a relatively dry year (1982). Table IV shows that soils are predominantly silty and clayey at McCook and Mead, respectively. In other words, Mead soil has a higher water holding capacity. We suspect that seasonal precipitation amount along with soil properties play important roles in these relationships. However, it is also clear that strengths of these correlations are not very strong and additional work is needed to better understand these interactions.

Cross-correlation analyses were also completed for the years with relatively higher correlations. For example, cross-correlation analyses for the 1998-99 growing season top soil layer and plant available SM for grass at Clay Center reports the highest estimate of 0.24 at 12 days lag. These estimates steadily decrease after 1 day lag and slightly increase on the 12th day, and then declines. Similar estimates for rainfed corn at Clay Center and McCook steadily decline with increasing lag. In other words, crosscorrelation using time lag does not show much promise in estimating plant available root zone SM based on the top layer soil water content.

\section{IMPLICATIONS OF RESULTS AND FINAL REMARKS}

This study provides a quantitative assessment of the relationship between near-surface SM and SM at various depths of the root zone under three land uses and contrasting hydroclimatic domains. A similar assessment was completed for near-surface SM and plant available root zone SM (total depth is $1.22 \mathrm{~m}$ ). In addition, it is suggested that these land uses are representative of predominant land uses of the region. Hence, these point-scale assessments would be helpful to understand large-scale root zone SM relationships. To accomplish

Table X. Inter-annual variations of relationship $(r)$ between top soil layer SM and plant available SM during growing season. Bold values indicate dry or wet years

\begin{tabular}{|c|c|c|c|c|c|c|c|c|c|}
\hline \multirow[t]{2}{*}{ Year } & \multicolumn{3}{|c|}{ McCook } & \multicolumn{3}{|c|}{ Clay center } & \multicolumn{3}{|c|}{ Mead } \\
\hline & Grass & Rainfed corn & Irrigated corn & Grass & Rainfed corn & Irrigated corn & Grass & Rainfed corn & Irrigated corn \\
\hline 1982 & $0 \cdot 014$ & $0 \cdot 25$ & $0 \cdot 10$ & 0.29 & 0.34 & $0 \cdot 16$ & 0.63 & 0.62 & 0.44 \\
\hline 1983 & 0.29 & 0.57 & 0.01 & $0 \cdot 16$ & 0.21 & $-0 \cdot 10$ & 0.23 & -0.07 & $-0 \cdot 10$ \\
\hline 1984 & $0 \cdot 26$ & 0.38 & $-\mathbf{0 . 3 0}$ & $0 \cdot 31$ & 0.48 & 0.13 & 0.26 & 0.40 & 0.40 \\
\hline 1985 & $0 \cdot 16$ & $0 \cdot 39$ & -0.03 & 0.008 & $0 \cdot 17$ & $0 \cdot 10$ & $0 \cdot 21$ & $0 \cdot 14$ & $0 \cdot 12$ \\
\hline 1986 & $0 \cdot 32$ & 0.51 & -0.14 & $-0 \cdot 16$ & $0 \cdot 35$ & 0.40 & 0.002 & 0.27 & $0 \cdot 17$ \\
\hline 1987 & -0.18 & 0.095 & $-0 \cdot 11$ & -0.09 & $0 \cdot 14$ & -0.07 & -0.09 & -0.07 & -0.13 \\
\hline 1988 & $-0 \cdot 10$ & 0.05 & -0.13 & -0.007 & 0.13 & 0.08 & 0.29 & 0.44 & 0.20 \\
\hline 1989 & $0 \cdot 12$ & $0 \cdot 10$ & $0 \cdot 01$ & $0 \cdot 20$ & $0 \cdot 19$ & $0 \cdot 15$ & $-0 \cdot 14$ & $0 \cdot 31$ & $0 \cdot 14$ \\
\hline 1990 & -0.03 & $0 \cdot 14$ & $-0 \cdot 30$ & 0.32 & 0.41 & $\mathbf{0} \cdot 32$ & -0.09 & $0 \cdot 35$ & $0 \cdot 20$ \\
\hline 1991 & 0.63 & 0.70 & 0.22 & 0.09 & $0 \cdot 34$ & 0.08 & -0.04 & $0 \cdot 25$ & $0 \cdot 37$ \\
\hline 1992 & $-0 \cdot 16$ & $0 \cdot 10$ & -0.21 & $0 \cdot 27$ & $0 \cdot 32$ & -0.06 & $-0 \cdot 37$ & $-0 \cdot 14$ & -0.08 \\
\hline 1993 & $\mathbf{0} \cdot 33$ & 0.72 & $\mathbf{0} \cdot 30$ & 0.20 & $0 \cdot 29$ & $0 \cdot 32$ & -0.09 & $0 \cdot 30$ & $0 \cdot 14$ \\
\hline 1994 & -0.21 & -0.24 & -0.32 & $0 \cdot 11$ & $0 \cdot 25$ & -0.46 & -0.09 & $0 \cdot 22$ & $0 \cdot 27$ \\
\hline 1995 & $0 \cdot 20$ & 0.42 & $0 \cdot 20$ & 0.086 & $0 \cdot 28$ & $0 \cdot 13$ & -0.13 & $0 \cdot 28$ & 0.40 \\
\hline 1996 & $0 \cdot 18$ & $0 \cdot 22$ & $0 \cdot 17$ & $0 \cdot 12$ & $-0 \cdot 12$ & $0 \cdot 25$ & $0 \cdot 0$ & 0.09 & $0 \cdot 10$ \\
\hline 1997 & $0 \cdot 31$ & $0 \cdot 38$ & 0.07 & 0.23 & $-0 \cdot 18$ & -0.01 & $-0 \cdot 20$ & 0.05 & $0 \cdot 37$ \\
\hline 1998 & $0 \cdot 24$ & $0 \cdot 51$ & $0 \cdot 1$ & 0.03 & $0 \cdot 21$ & -0.04 & $-0 \cdot 18$ & 0.01 & $0 \cdot 15$ \\
\hline
\end{tabular}


the objectives a soil-water and energy-balance process model was applied to simulate SM at a climatic timescale (1982-1999). The model simulations and resultant variations of SM over seasons and for different land uses also suggest that SM estimates are satisfactory and comparable to findings by other investigators (e. g. Georgakakos and Bae, 1994; Georgakakos et al., 1995; Scott et al., 2000).

Results of this study suggest that temporal distribution of SM at various depths of the root zone is a function of soils, land use and prevailing hydroclimatic conditions. The most prominent outcome of this study is that correlation (0 day lag) and cross-correlation (more than 0 day lag) between near-surface SM and SM at various depths ranges from weak to moderately strong. This is also true for the relationship between near-surface SM and plant available root zone SM. It is found that rainfed land uses have relatively higher correlation and cross correlation than a human modified (irrigated) land use. Cross-correlations are relatively higher for all land uses with lags of 18 to 119 days. Correlation between the top and second layers for all land uses increases. Similar results were found during cross-correlation analyses with a shorter lag of days. In other words, results are promising. As expected, the strength of these relationships varies from year-to-year and compared with the climate-scale, the correlations at an annual-scale are greater.

The findings of this study indicate that the dynamics associated with SM variations through the depths of the root zone are complex. In other words, the results are in general agreement with $\mathrm{Li}$ and Islam (2002), Wu et al. (2002), Mahmood and Hubbard (2004) and HPRCC (2005). Thus, it is possible to suggest that estimation or prediction of SM for the whole root zone or for various depths based on near-surface SM would be difficult. Several studies have shown application of remote sensing in estimating near-surface SM (Vinnikov et al., 1999; Jackson et al., 2002), and there is a tendency to equate this near-surface SM to the whole root zone. However, our results and several studies by other groups (Santanello and Carlson, 2001) clearly show that this assumption is not justified. This also suggests that we need to complete further comprehensive studies on this issue using both modelled and observed data in order to reach a better understanding of the complex system.

\section{ACKNOWLEDGEMENTS}

The authors would like to thank Western Kentucky University Faculty Research Council for partly funding this research. We also acknowledge comments from the reviewers which helped to improve this paper.

\section{REFERENCES}

Adegoke JO, Carleton AM. 2002. Relations between soil moisture and satellite vegetation indices in the U. S. corn belt. Journal of Hydrometeorology 3: 395-405.
Camargo MBP. 1993. Determination of the water balance components and drought sensitivity indices for a sorghum crop. $\mathrm{PhD}$ dissertation, University of Nebraska-Lincoln, $131 \mathrm{pp}$.

Camargo MBP, Hubbard KG, Flores-Mendoza F. 1994. Test of a soil water assessment model for a sorghum crop under different irrigation treatments. Bragantia Campinas 53: 95-105.

Campbell GS. 1985. Soil Physics with Basic. Elsevier: New York.

Cherkauer KA, Lettenmaier DP. 1999. Hydrologic effects of frozen soils in the upper Mississippi River basin. Journal of Geophysical Research 104: 19 599-19 610

Crawford TM, Stensrud DJ, Carlson TN, Capehart WJ. 2000. Using a soil hydrology model to obtain regionally averaged soil moisture values. Journal of Hydrometeorology 1: 353-363.

Dirmeyer PA. 1999. Assessing GCM sensitivity to soil wetness using GSWP data. Journal of the Meteorological Society of Japan 77(1B): $367-385$.

Dirmeyer PA. 2000. Using Global Soil Wetness Dataset to improve seasonal climate simulation. Journal of Climate 13: 2900-2922.

Dirmeyer PA, Zeng FJ, Ducharne A, Morrill JC, Koster RA. 2000. The sensitivity of surface fluxes to soil water content in three land surface schemes. Journal of Hydrometeorology 1: 121-134.

Douville H, Chauvin F, Boroqua H. 2001. Influence of soil moisture on the Asian and African Monsoons. Part I: Mean monsoon and daily precipitation. Journal of Climate 14: 2381-2403.

Entin JK, Robock A, Vinnikov Y, Zabelin V, Liu S, Namkhai A, Adyasuren T. 1999. Evaluation of Global Soil Wetness Project soil moisture simulations. Journal of the Meteorological Society of Japan 77(1B): $183-198$

Findell KL, Eltahir EAB. 2003a. Atmospheric controls on soil moistureboundary layer interactions. Part I: Framework development. Journal of Hydrometeorology 4: 552-569.

Findell KL, Eltahir EAB. 2003b. Atmospheric controls on soil moistureboundary layer interactions. Part II: Feedbacks within the continental United States. Journal of Hydrometeorology 4: 552-569.

Georgakakos KP, Bae D-G. 1994. Climatic variability of soil water in the American Midwest: Part 2. Spatio-temporal analyses. Journal of Hydrology 162: 379-390.

Georgakakos KP, Bae D-G, Cayan DR. 1995. Hydroclimatology of continental watersheds. 1. Temporal analyses. Water Resources Research 31: 655-675.

Hong S, Kalnay E. 2000. Role of sea surface temperature and soilmoisture feedback in the 1998 Oklahoma-Texas drought. Nature $\mathbf{4 0 8}$ $842-844$

Hong S-Y, Pan H-L. 2000. Impact of soil moisture anomalies on seasonal, summertime circulation over North America in a regional climate model. Journal of Geophysical Research 105: 29 625-29 634.

Huang J, Van den Dool HM, Georgakakos KP. 1996. Analysis of modelcalculated soil moisture over the United States (1931-1993) and applications to long-range temperature forecasts. Journal of Climate 9: $1350-1362$.

Jackson TJ, Hsu AY, O’Neill PE. 2002. Surface soil moisture retrieval and mapping using high-frequency microwave satellite observations in the Southern Great Plains. Journal of Hydrometeorology 3: 688-699.

Kincaid DC, Heerman DF. 1974. Scheduling Irrigations using a Programmable Calculator. USDA-ARS-NC-12, U. S. Government Print.ing Office: Washington, DC

Koster RA, Suarez MJ. 2003. Impact of land surface initialization on seasonal precipitation and temperature prediction. Journal of Hydrometeorology 4: 408-423.

Koster RA, Suarez MJ, Heiser M. 2000. Variance and predictability of precipitation at seasonal-to-interannual timescales. Journal of Hydrometeorology 1: 26-46.

Legates DR, McCabe Jr. GJ. 1999. Evaluating the use of 'goodness-offit' measures in hydrologic and hydroclimatic model validation. Water Resources Research 35: 233-241.

Li J, Islam S. 2002. Estimation of root zone soil moisture and surface fluxes partitioning using near surface soil moisture measurements Journal of Hydrology 259: 1-14.

Lohmann D, Lettenmaier DP, Liang X, Wood EF, Collaborators. 1998. The project for intercomparison of land-surface parameterization schemes (PILPS) phase 2(c) Red-Arkansas river basin experiment: 3 . Spatial and temporal analysis of water fluxes. Global Planetary Change 19: $161-179$.

Mahmood R, Hubbard KG. 2002. Anthropogenic land use change in the North American tall grass-short grass transition and modification of near surface hydrologic cycle. ClimateResearch 21: 83-90.

Mahmood R, Hubbard KG. 2003. Simulating sensitivity of soil moisture and evapotranspiration under heterogeneous soils and land uses. Journal of Hydrology 280: 72-90. 
Mahmood R, Hubbard KG. 2004. An analysis of simulated long-term soil moisture data for three land uses under contrasting hydroclimatic conditions in the Northern Great Plains. Journal of Hydrometeorology 5: $160-179$.

Mahmood R, Hubbard KG, Hou Q. 2001. Soil moisture monitoring and modeling in the Great Plains. In Automated Weather Stations for Applications in Agriculture and Water Resources Management: Current Use and Future Perspectives, Hubbard KG, Sivakumar MVK (eds). High Plains Climate Center: Lincoln, NE; and World Meteorological Organization: Geneva; 163-171.

Mahmood R, Hubbard KG, Carlson C. 2002. Land use change and modification of near-surface thermal records in the Northern Great Plains. Bulletin of the American Meteorological Society 83: 504.

Mahmood R, Hubbard KG, Carlson C. 2004. Modification of growing season surface temperature records in the Northern Great Plains due to land use transformation: verification of modeling results and implication for global climate change. International Journal of Climatology 24: 311-327.

McCuen RH. 1982. A Guide to Hydrologic Analysis using SCS Methods. Prentice-Hall: Englewood Cliffs, NJ; 9-18.

Meyer SJ, Hubbard KG, Wilhite DA. 1993a. A crop-specific drought index for corn: I. Model development and validation. Agronomy Journal 85: 388-395.

Meyer SJ, Hubbard KG, Wilhite DA. 1993b. A crop-specific drought index for corn: II. Application in drought monitoring and assessment. Agronomy Journal 85: 396-399.

Mitchell K, Marshall C, Lohmann D, et al. 2000. The collaborative GCIP Land Data Assimilation (LDAS) project and supportive NCEP uncoupled land surface modeling initiative. Proceedings, 15th Conference on Hydrology 9-14 January 2000, Long Beach, CA.

Morrill JC, Dickinson RE, Hahmann AN. 1999. Sensitivity of a land surface model to the diurnal distribution of downward longwave radiation. Journal of the Meteorological Society of Japan 77(1B): $265-279$.

Penman HL. 1948. Natural evapotranspiration from open water, bare soil and grass. Proceedings Royal Society of London A 193: 120-145.

Pitman AJ, Zhao M, Desborough CE. 1999. Investigating the sensitivity of a land surface scheme's simulation of soil wetness and evaporation to spatial and temporal leaf area index variability within the Global Soil Wetness Project. Journal of the Meteorological Society of Japan 77(1B): 281-290.

Qiu Y, Fu B, Wang J, Chen L. 2001. Soil moisture variation in relation to topography and land use in a hillslope catchment of the Loess Plateu, China. Journal of Hydrology 240: 243-263.
Qu W, Henderson-Sellers A, Pitman AJ, Chen TH, Collaborators. 1998. Sensitivity of latent heat flux from PILPS land-surface schemes to perturbations of surface air temperature. Journal of Atmospheric Science 55: 1909-1927.

Robinson JM, Hubbard KG. 1990. Soil water assessment model for several crops in the high plains. Agronomy Journal 82: 1141-1148.

Robock A, Schlosser CA, Vinnikov KY, Speranskaya NA, Entin JK. 1998. Evaluation of AMIP soil moisture simulations. Global Planetary Change 19: 181-208.

Ronda RJ, Hurk B, Van Den JJM, Holtslag AAM. 2002. Spatial heterogeneity of the soil moisture content and its impact on surface flux densities and near-surface meteorology. Journal of Hydrometeorology 3: $556-570$.

Santanello JA, Carlson TB. 2001. Mesoscale simulations of rapid soil drying and its implications for predicting daytime temperature. Journal of Hydrometeorology 2: 71-88.

Schar C, Luthi D, Beyerle U, Heise E. 1999. The soil-precipitation feedback: A process study with a regional climate model. Journal of Climate 12: 722-741.

Schlosser CA, Milly PCD. 2002. A model-based investigation of soil moisture predictability and associated climate predictability. Journal of Hydrometeorology 3: 483-501.

Scott RL, Shuttleworth WJ, Keefer TO, Warrick AW. 2000. Modeling multiplayer observations of soil moisture recharge in the semiarid American Southwest. Water Resources Research 36: 2233-2247.

Srinivasan G, Robock A, Entin JK, et al. 2000. Soil moisture simulations in revised AMIP models. Journal of Geophysical Research 105: 26 635-26 644

USGCRP. 2001. A Plan for a New Science Initiative on the Global Water Cycle. U.S. Global Change Research Program: Washington, DC.

Vinnikov KY, Robock A, Qiu S, et al. 1999. Satellite remote sensing of soil moisture in Illinois, USA. Journal of Geophysical Research 104: 4145-4168.

Wang W, Kumar A, 1998. A GCM assessment of atmospheric seasonal predictability associated with soil moisture anomalies over North America. Journal of Geophysical Research 103: 28 637-28 646.

Willmott CJ. 1981. On the validation of models. Physical Geography 2: 184-194.

Wu W, Geller MA, Dickinson RE. 2002. The response of soil moisture to long-term variability of precipitation. Journal of Hydrometeorology 3: $604-613$. 